\title{
An Analysis of the Correlation between the Changes in Satellite DNA Methylation Patterns and Plant Cell Responses to the Stress
}

\author{
Darina A. Sokolova, Galina S. Vengzhen, Alexandra P. Kravets \\ Department of Plant Biophysics and Radiobiology, Institute of Cell Biology and Genetic Engineering, \\ National Academy of Science of Ukraine, Kiev, Ukraine \\ Email: kaplibra@gmail.com
}

Received July 25, 2013; revised August 22, 2013; accepted August 29, 2013

Copyright (C) 2013 Darina A. Sokolova et al. This is an open access article distributed under the Creative Commons Attribution License, which permits unrestricted use, distribution, and reproduction in any medium, provided the original work is properly cited.

\begin{abstract}
The differences in satellite DNA methylation pattern of corn seedlings with various spontaneous chromosome aberration yields and changes in methylation pattern of these DNA sequences under different exposure modes of acute UV-C and chronic gamma-irradiations have been investigated. The obtained experimental data and the conducted correlation analysis demonstrated the significant correlation between the satellite DNA methylation pattern varieties and chromosome aberration yields under various stress exposure modes. The role of satellite DNA methylation pattern variability and its changing in key responses to stress such as mobile elements' activation, cell's passage of checkpoints, and homological repair was discussed.
\end{abstract}

Keywords: Stress Response; Plant Resistance; Satellite DNA Methylation Pattern; Brave-Pirson Linear Correlation

\section{Introduction}

Changing organism's resistance to stress factors, various reactions, which role in this process depends on factor's acting rate, duration and/or periodicity. Complexity of interactions in stress reactions can also be attributed to hierarchical-structural and functional, organism organization, where different processes have various sensitivities and times of development.

DNA methylation is one of the most important and polyfunctional mechanisms of biological regulation, which has a great significance in such epigenetic processes as genomic imprinting, differentiation, apoptosis and morphogenesis, aging of an organism, regulation of mobile elements' activity [1-3].

It is also known that methylation of cytosine is the natural factor of mutagenesis [2] and at the same time it is a factor affecting regional DNA structure's organization that is necessary for successful passage of enzymatic reactions, related to reading-out of information and reparation.

Plants contain most of methylated cytosine (up to $30 \%$ ); the DNA methylation of these organisms is the result of functioning four groups of methyltransferases [2] that provide a great methylation sites' variety.
It may be claimed that various methylation pathways can play important roles in stress response reactions and rearrangements of their resistance, whereas in alternative "to run or to fight" these organisms choose "fighting" at all levels of organization. A number of last investigations show some changes in level and pattern of DNA methylation under biotic $[3,4]$ and different forms of abiotic stress-dryness [3], salinization [3-6], radiation exposures with various dose rates [7-9] and duration $[8,10]$.

Polyfunctional of DNA methylation process also allows different ways of its participation both in failure (e.g. activization of mobile elements, initialization of genome instability) and/or formation of active protective reactions, associated with metabolism reorganization. Thus changes in DNA methylation level and/or pattern under different stress exposure [3-10] still require specification of their biological significance.

The appearance of DNA micro array technology made a revolution in studying changes in gene expression under stress exposures. Obtained data have confirmed the connection between changes in methylation pattern of transcribed DNA with changes in expression of major gene groups, metabolism rearrangements and resistance changes under stress exposure [11-13]. 
In parallel with studying the majority of changes in transcribed DNA methylation pattern in their responsiveness under stress exposures, great changes in satellite DNA methylation pattern have been detected [14].

It is known that satellite DNA is true to type component of eukaryotic genome. It consists of tandem organized repeats, and it is never transcribed or encoded proteins and is located in heterochromatin part of chromosome [15]. A high methylation level of satellite DNA' cytosine has been shown but satellite DNA's biological importance still hasn't been understood. A question about biological role of changes in DNA methylation pattern under stress exposures and subsequent changes of cell resistance is also unexplored now.

The paper is dedicated to investigate the connection between variability of satellite DNA methylation pattern and spontaneous chromosome aberration' rate as well as changes in methylation pattern of satellite DNA under different modes of acute UV-C and chronic gamma-exposure of seedlings. The study of DNA methylation pattern is performed by comparing the chromosomal aberrations yielded in meristematic tissues as the independent index that allowed to estimate the plant cell resistance.

\section{Material and Method}

The investigation of connection between satellite DNA methylation statuses with plant cell resistance to stress exposure was carried out in three series of experiments:

1) Acute UV-C exposure of epigenetically different corn seedlings (EDS). Preliminary three groups of corn' seedlings with different germination rates were empiric selected: fast germinating (F-G), middle germinating (M$\mathrm{G}$ ), and slowly germinating (S-G). A great connection between germination rates and differences in transcribed DNA methylation pattern has been preinstalled;

2) Acute UV-C exposure in the mode of "adaptive exposure-challenge exposure" with different ranges between the adaptive UV-C irradiation and challenge one (different mode UV-C exposure). The adaptive dose was $1 \mathrm{~kJ} / \mathrm{m}^{2}$ and the challenge one $-6.2 \mathrm{~kJ} / \mathrm{m}^{2}$;

Combined exposure: preliminary chronic gamma-exposure of dry seeds with various accumulative dose and subsequent seedlings acute UV-C exposure.

Two intervals between the adaptive UV-C irradiation and challenge one were investigated: 4 hours and 24 hours. The necessity to expose seedlings in challenge dose $\left(6.2 \mathrm{~kJ} / \mathrm{m}^{2}\right)$ and whole dose $\left(7.2 \mathrm{~kJ} / \mathrm{m}^{2}\right)$ in the same physiological state was taken into account. Thus such variants of irradiation were used:

1) Non UV-C irradiated seedlings;

2) Adaptive exposure $\left(1 \mathrm{~kJ} / \mathrm{m}^{2}\right)$;

3) Adaptive exposure, in 4 hours-challenging one (6.2 $\left.\mathrm{kJ} / \mathrm{m}^{2}\right)$;
4) Whole dose exposure $\left(7.2 \mathrm{~kJ} / \mathrm{m}^{2}\right)$; exposure simultaneously with the challenging irradiation of variant 3 ;

5) Adaptive exposure, in 24 hours - challenging one $\left(6.2 \mathrm{~kJ} / \mathrm{m}^{2}\right)$;

6) Whole dose exposure $\left(7.2 \mathrm{~kJ} / \mathrm{m}^{2}\right)$; irradiation simultaneously with the challenging irradiation of variant 5 .

Such ways of irradiation were conducted both with seedlings from non preliminary gamma-irradiated seeds (NPI) and with seedlings from preliminary gamma-irradiated seeds (PI).

The study was performed using 3 - 7-days maize seedlings, sort Titan. Seeds' sprouting was conducted on bottom plates with wet filter paper, in thermostat under the temperature $+23^{\circ} \mathrm{C}-+24^{\circ} \mathrm{C}$. Bactericidal irradiator of the open type OBN-150M (Ukraine) with Philips Special TUV $30 \mathrm{~W}$ lamps was used. Three-day seedlings were exposed by UV-C in whole doses of $7.2 \mathrm{~kJ} / \mathrm{m}^{2}$ (dose rate was $6.2 \mathrm{~W} / \mathrm{m}^{2}$ ) in the range 4 hours and 24 hours between adaptive and challenging irradiation as described above.

A glass container with ${ }^{137} \mathrm{CsCl}_{2}$ was used for investigation of chronic exposure effects; dry seeds were exposed with dose rate $30 \mathrm{mR} / \mathrm{h}$, accumulated dose reached $3.5 \mathrm{~Gy}$.

The apical root meristems were used as an object for cytogenetic analysis. Sampling was carried out on the 4th day after irradiation. Detached apexes have been put to the Brodsky' fixative (acetic acid: ethanol: formalin $=0.3: 1: 3$ ) for two hours with following washing by $70 \%$ ethanol (3 4 times). Maceration has been performed by alkaline hydrolysis with $20 \% \mathrm{NaOH}$ over two hours. Then preparations have been washed in distilled water for 15 minutes. Staining was carried out by acetoarsein and hydrochloric acid mixture (acetoarsein: $1 \mathrm{M} \mathrm{HCl}=1: 1$ ) over $16-18$ hours. Stained samples have been washed in $45 \%$ $\mathrm{CH}_{3} \mathrm{COOH}$ with following preparation the crushed specimens. Ten alternative apexes were used and $5-10$ thousands of cells were analyzed for every variant. The unstable chromosomal aberrations were detected using anaphase-telophase technique due to plant tissue specificity. In spite of this cells' sampling has averaged over 300 - 350 chromosomal aberrations during the anaphase in each preparation. A cytogenetic analysis was conducted on the light microscope "Jenaval" (Germany). Independent cytogenetic analisis was performed 8 times. Significance level $(\alpha)$ of assessment is 0.05 .

Isolation of DNA was performed from the 6-day-old corn seedlings with the set of reagents Diatom ${ }^{\mathrm{TM}}$ DNA Prep100 based on NucleoS-sorbent. The standard protocol for DNA extraction provided by the manufacturer was used. The concentration of DNA solution was measured by BioPhotometer Plus Eppendorf v.1.35 using standard technique [16,17].

The PCR was carried out in the four-channel DNA- 
amplifier "Tercik" ("DNA-Technology", Moscow). One primer has been used: inter simple sequence repeatISSR (15-soro, sequence-5'-AC-AC-AC-AC-AC-AC-AC$\mathrm{AC}-<\mathrm{C}>-3$ '), were synthesized by company "Metabion" (Germany) [18].

The restriction analysis as well as the PCR was carried out in the four-channel DNA-amplifier "Tercik" ("DNATechnology", Moscow). Two types of restriction enzymes-isoschizomers were used: HpaII (5'.C CGG.3'), MspI (5'.C CGG.3') and restrictase MboI ("Fermentas", Germany). Reactions were performed according to the conventional manual by the supplier (Table 1).

The reaction mixture for the HpaII-analysis (total volume $25 \mu \mathrm{l}$ ) contained: $0.2 \mu \mathrm{l} \mathrm{HpaII}, 2.0 \mu \mathrm{l} 10 \mathrm{xBuffer}$ Tango, $1.5 \mu \mathrm{g}$ total DNA and $17.7 \mu \mathrm{l}$ deionized water. The mixture has been covered with the $20 \mu \mathrm{l}$ of mineral oil.

The reaction mixture for the MspI-analysis (total volume $25 \mu \mathrm{l}$ ) contained: $0.6 \mu \mathrm{l} \mathrm{MspI,} 2.0 \mu \mathrm{l}$ 10xBuffer Tango, $1.5 \mu \mathrm{g}$ total DNA and $17.1 \mu \mathrm{l}$ deionized water. The mixture has been covered with the $20 \mu \mathrm{l}$ of mineral oil.

The reaction mixture for the MboI-analysis (total volume $25 \mu \mathrm{l}$ ) contained: $0.2 \mu \mathrm{l} \mathrm{MboI,} 2.0 \mu \mathrm{l} 10 \mathrm{xBuffer}$ Tango, $1.5 \mu \mathrm{g}$ total DNA and $17.7 \mu \mathrm{l}$ deionized water. The mixture has been covered with the $20 \mu \mathrm{l}$ of mineral oil.

The conditions for restriction reactions were: 16 hours under $37^{\circ} \mathrm{C}$, then $20 \mathrm{~min}$ under $65^{\circ} \mathrm{C}$ (for HpaII and MboI) and $20 \mathrm{~min}$ under $80^{\circ} \mathrm{C}$ (for MspI) to stop the reactions.

Products of PCR and restriction analysis were separated in $1.0 \%$ agarose gel with TBE-buffer at the presence of ethidium bromide, and visualized in UV-transilluminator. The same volume of PCR and restriction products $(10 \mu \mathrm{l})$ was brought into the gel pockets. The FastRuler High Range DNA Ladder ("Fermentas", Germany) with fragments' length 10,000, 4000, 2000, 1000 and 500 base pairs and the FastRuler Low Range DNA Ladder ("Fermentas", Germany) with fragment length $1500,850,400,200$ and 50 base pairs were used as a molecular weight markers. Independent ISSR-PCR was performed 8 times also.

Experimental findings statistical analysis-the variance value and the Brave-Pirson's correlation coefficientwere calculated with traditional method [19].

Table 1. Restriction enzymes and their sites of recognition/restriction.

\begin{tabular}{|c|c|}
\hline Restriction enzyme & Sites of recognition/restriction \\
\hline MspI & $5^{\prime} \mathrm{C} \ldots \mathrm{C}^{*} \mathrm{CG}, \mathrm{C} \ldots 5^{\prime}$ \\
\hline \multirow[t]{2}{*}{ HpaII } & $5^{\prime}, \ldots C^{*} \mathrm{CGG} \ldots 3$ ' \\
\hline & $3^{\prime} \mathrm{G} \ldots \mathrm{G} \mathrm{C} * \mathrm{C} \ldots 5^{\prime}$ \\
\hline \multirow[t]{2}{*}{ MboI } & $5^{\prime} \ldots \mathrm{C} * \mathrm{CGC} \ldots 3^{\prime}$ \\
\hline & $3^{\prime} \ldots \mathrm{CT} \ldots \mathrm{AG} * \mathrm{C} \ldots 5{ }^{\prime}$ \\
\hline
\end{tabular}

\section{Results and Discussion}

The obtained cytogenetic data pointed out major varieties in chromosome aberrations' yield (Ab, \%) appeared among groups F-G, M-G and S-G seedling (Figure 1).

The electrophoregram of isolated DNA nativity is shown in Figure 2.

The electrophoregram of native DNA amplification with ISSR primers (Figure 3) shows specific differences

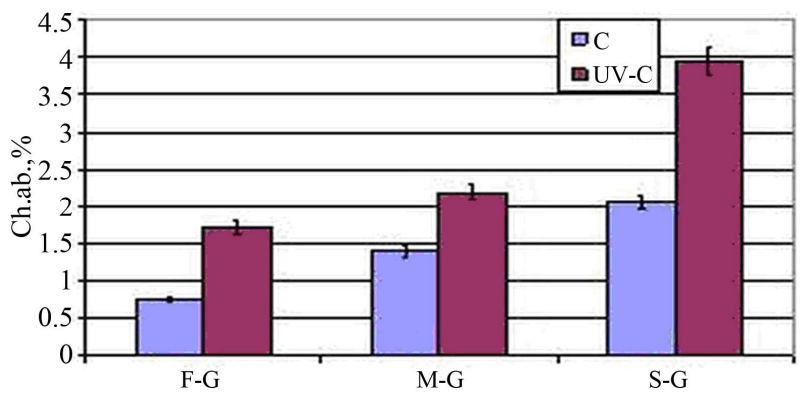

Figure 1. The chromosome aberration yield $(\alpha=0.05)$ in root meristem of corn seedlings with various germination rates; C-non-irradiated seedlings; UV-C-seedlings irradiated with UV-C.

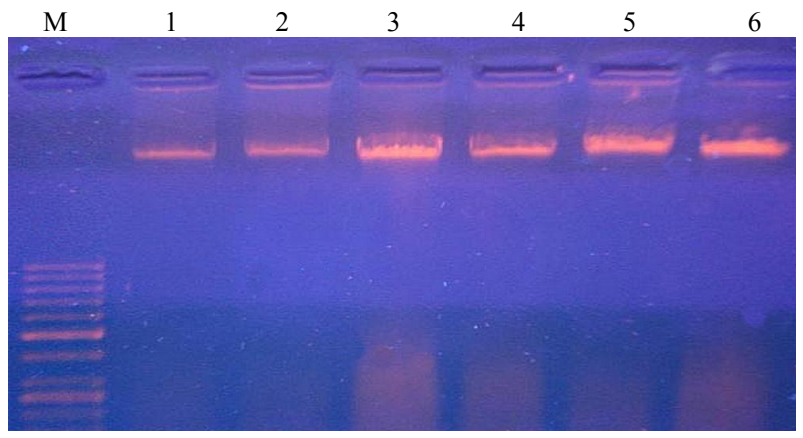

Figure 2. The electrophoregram of isolated DNA quality. M-high-molecular-weight marker; 1-“FG" sample; 2"FG + UV-C" sample; 3-"MG" sample; 4-"MG + UV-C" sample; 5-"SG" sample; 6-“SG + UV-C" sample.

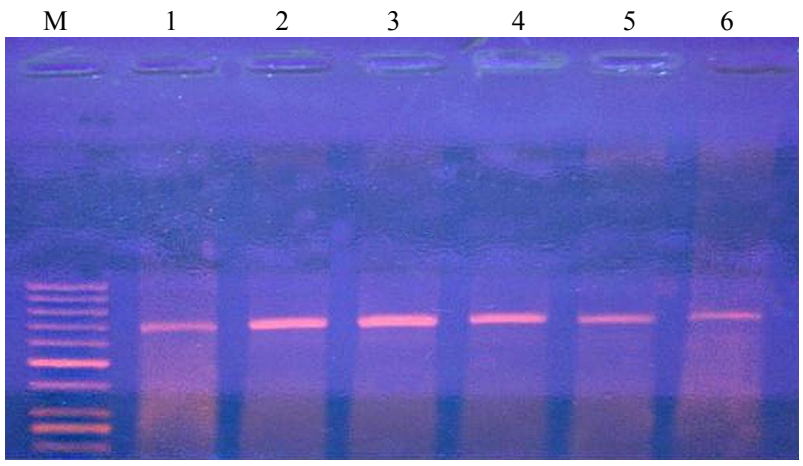

Figure 3. The electrophoregram of native DNA amplification products with ISSR primers. $M-$ high-molecular-weight marker; 1-"FG" sample; 2-“FG+UV-C" sample; 3"M-G" sample; 4-"M-G + UV-C" sample; 5-"SG" sample; 6-"S-G + UV-C" sample. 
in amplicons range of irradiated and unirradiated fastgrowing seedlings (positions 1 and 2).

These data do not contradict with data about good nativity of isolated DNA. The most appropriate explanation is connected with appearance of damage during PCR that might indirectly evidence about low methylation level of this DNA part in fast-growing seedlings resulting to greater vulnerability of these DNA samplers 1 .

An electrophoregram of the amplification products obtained by ISSR-PCR of the MspI restriction products (Figure 4) illustrated the differences in DNA methylation pattern among seedlings with various germination rates (positions 1, 3, 5).

The electrophoregram of fast-germinated seedlings (FG, position 1) had four distinct groups of amplicons with almost the same number of DNA fragments. The groups of amplicons (positions 3 and 5) for variants "M-G" and "S-G" had the same molecular weight, but different number of DNA fragments.

The comparison of positions 1 and 2, 3 and 4, 5 and 6 of this electrophoregram (Figure 4) shows great changes of satellite DNA methylation pattern after irradiation. Positions 2, 4, 6 are also differing from each others that correspond to increased chromosome aberration' yield after UV-C exposure (Figure 1).

Also considerable differences between methylation patterns of satellite DNA of seedlings that initially had various germination rates (positions $1,3,5$ ) were observed in separating amplification products of MboI restricts with ISSR-primers (Figure 5). There was just one type of amplicons for "F-G" seedlings and great differences between "M-G" and "S-G" variants. Electrophoregram for "M-G" seedlings had four distinct groups of amplicons with comparatively more high-molecular fragments.

The comparison of positions 1 and 2, 3 and 4, 5 and 6 of this electrophoregram (Figure 5) shows great changes of satellite DNA methylation pattern after irradiation.

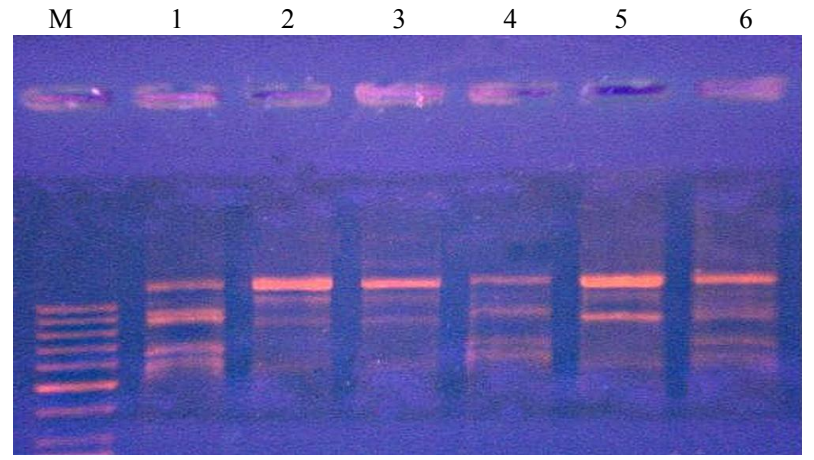

Figure 4. The electrophoregram of the amplification products obtained by ISSR-PCR of the MspI restriction products. M-high-molecular-weight marker; 1- "FG" sample; 2-"FG + UV-C" sample; 3-"MG" sample; 4-"MG + UV-C" sample; 5-“SG" sample; 6-"SG + UV-C" sample.

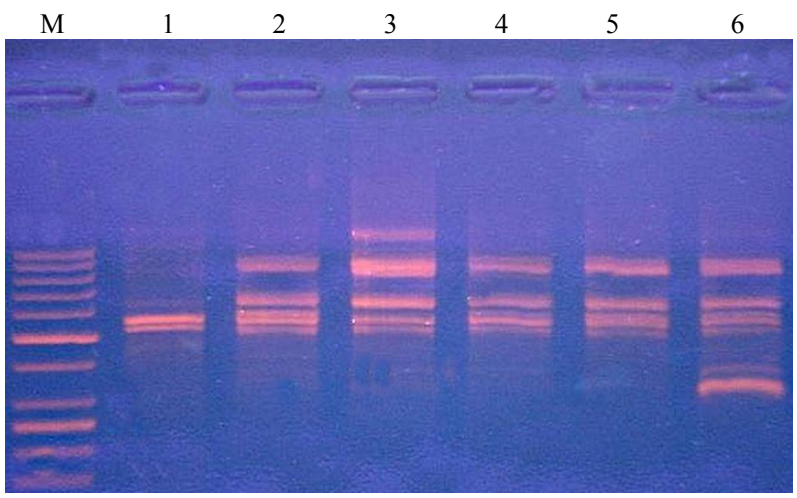

Figure 5. The electrophoregram of the amplification products obtained by ISSR-PCR of the MboI restriction products. M-high-molecular-weight marker; 1-“FG" sample; 2-"FG + UV-C" sample; 3-"MG" sample; 4-"MG + UV-C" sample; 5-“SG" sample; 6-"SG + UV-C" sample.

Positions 2, 4 do not have major differences from each other. The greatest difference is observed between positions 4 and 6. Such differences correspond to various increasings in the chromosome aberration' yield after UVC exposure (Figure 1).

Thus original difference in satellite DNA methylation pattern is connected to differences in pattern changes under irradiation exposure and chromosome aberration' yield. This indicates both different effectiveness of repair processes or various original sensitiveness to damage.

Consider the data about acute UV-C exposure mode "adaptive-challenging irradiation" as well as combined exposure whereby seedlings growing from preliminary gamma-irradiated seeds have been exposed.

Chromosome aberration yield in root meristematic tissue (Figure 6) indicates to major differences in appearance of seedlings' adaptive reactions that have grown from unexposed and gamma-exposed seeds. Chronic radiation exposure of seeds causes increase of chromosome aberration rate in seedlings' root meristematic tissues. UV-C exposure of seedlings from preliminary unirradiated seeds with adaptive dose leads to increasing chromosome aberration yield whereas exposure of seedlings from preliminary irradiated seeds causes the hormetic effect. Exposure mode "adaptive, in 4 hours-challenging" causes the appearance of adaptive response for seedlings without preliminary irradiation exposure; with interval in 24 hours between adaptive and challenging exposure the adaptive response haven't been observed. Seedlings from preliminary irradiated seeds didn't show the adaptive response with both intervals between adaptive and challenging irradiation.

An explanation of such phenomena from the standpoint about meristematic tissue' heterogeneity and possibility of two forms of repopulation renewal is given in paper [14]. The object of this study is to compare stability changes to stress factor affecting and changes in sat- 


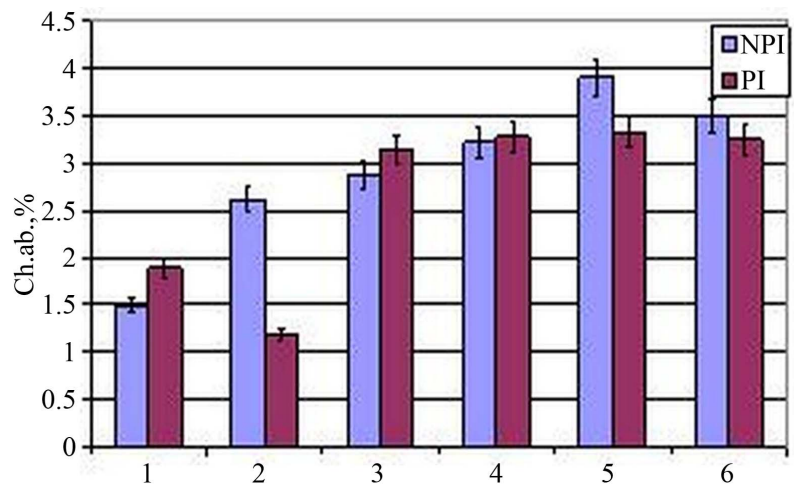

Figure 6. The chromosome aberration yield $(\alpha=0.05)$ in root meristem of corn seedlings from non preliminary gamma-irradiated seeds (NPI), and preliminary gammairradiated seeds, ( PI ) with UV-C irradiation mode as described in "Material and Methods".

ellite DNA methylation pattern.

The electrophoregrams of DNA quality checking are shown in Figure 7. These results demonstrate the absence of meaningful DNA fragmentation that would take a place in apoptosis inducing by UV-C irradiation.

The electrophoregram of native DNA amplification shows specific differences in comparison with all other variants of amplicon's range for variant "adaptive-challenge exposure in 24 hours" (Position 6). The most appropriate explanation is connected to appearance of ulterior (single-stranded) injuries during PCR. It's essential that the features of DNA fragmentation are observed in a variant exposed with full dose at a time.

For Figures 7-11: 1. Total control (NPI and non UV-C irradiated seedlings); 2 . NPI + adaptive exposure; 3 . NPI + adaptive exposure, in 4 hours-challenging one; 4 . NPI + whole dose exposure $\left(7.2 \mathrm{~kJ} / \mathrm{m}^{2}\right)$; exposure simultaneously with the challenging irradiation of variant 3 ); 5 . NPI + adaptive exposure, in 24 hours-challenging one; 6 . $\mathrm{NPI}+$ whole dose exposure; irradiation simultaneously with the challenging irradiation of variant $5 ; 7$. PI + non UV-C irradiation; 8. PI + adaptive exposure; 9. PI + adaptive exposure, in 4 hours-challenging one;10.PI + whole dose exposure; exposure simultaneously with the challenging irradiation of variant 3 and 9); 11. PI + adaptive exposure, in 24 hours-challenging one; 12. PI + whole dose exposure; irradiation simultaneously with the challenging irradiation of variants 5 and 11 .

The electrophoregram of MboI restricts' ISSR amplification shows various differences in DNA methylation patterns according to exposure mode. Comparison of positions 1 (seedlings from seeds without preliminary irradiation) and 7 (seedlings from preliminary gammairradiated seeds) indicates to major differences in range of amplicons: as a result of dry seeds chronic exposure the satellite DNA methylation pattern of seedlings shows some complication on electrophoregram because of ap-

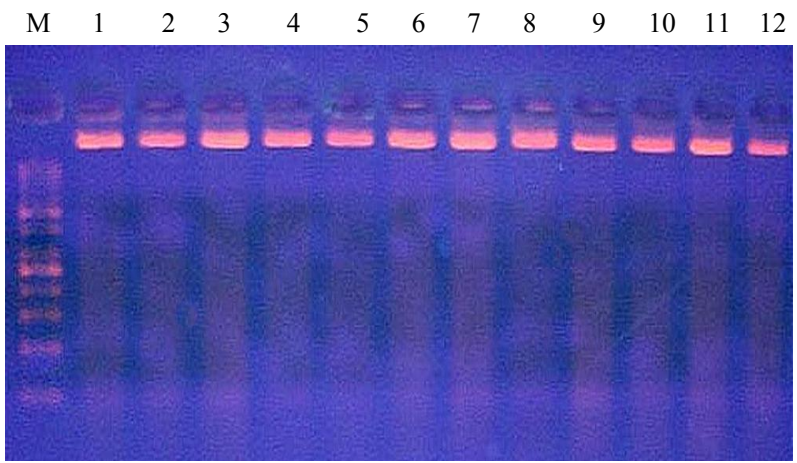

Figure 7. The electrophoregram of isolated DNA quality.

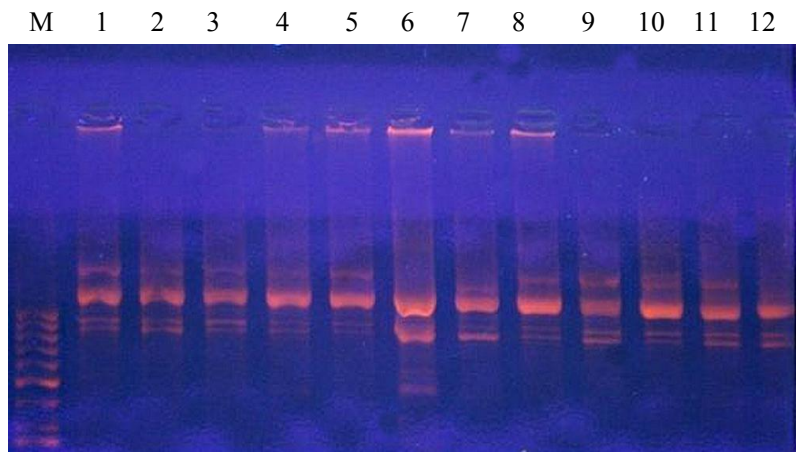

Figure 8. The electrophoregram of native DNA ISSR-amplification.

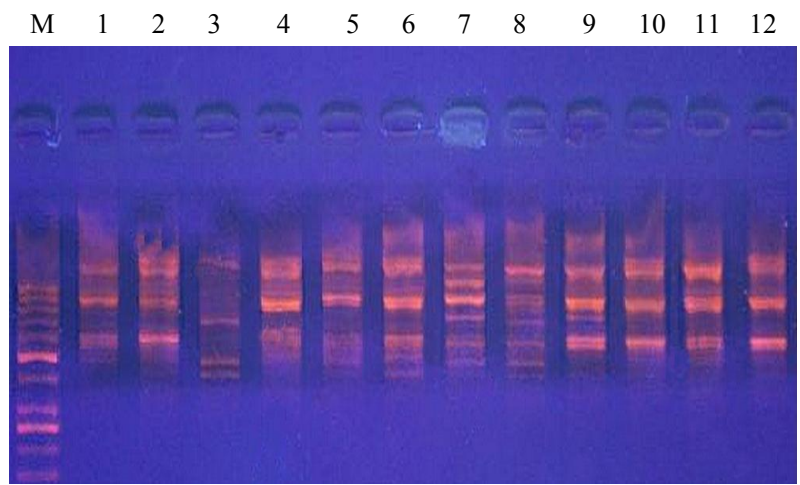

Figure 9. The electrophoregram of MboI restricts' ISSR amplification.

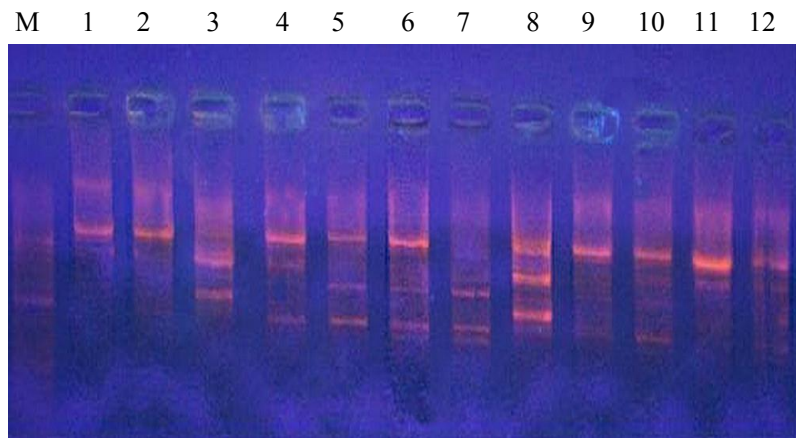

Figure 10. The electrophoregram of ISSR-amplification of MspI restricts. 


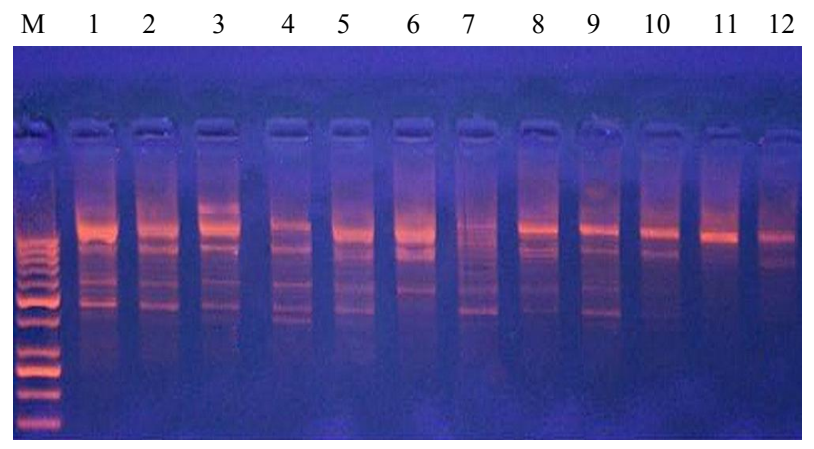

Figure 11. The electrophoregram of HpaII-restricts ISSRamplification.

pearance of amplicons with low and middle weight. It's essential that variants $9-12$ show identical ranges and parallels with the same chromosome aberration yield in the variants are also possible (Figure 6).

The electrophoregram of ISSR-amplification of MspI restricts shows various changes in DNA methylation pattern according to exposure mode. Comparison of positions 1 (seedlings from seeds without preliminary irradiation) and 7 (seedlings from preliminary gamma-exposed seeds) indicates to major differences in amplicons range: after dry seeds' chronic irradiation satellite DNA methylation pattern leads to great complication of electrophoregram because of appearing low-weight amplicons indicated to increase of restriction MspI sites. Major difference of $8^{\text {th }}$ variant is observed, which demonstrates hormesis effect in terms of chromosome aberration yield. It's essential that variants 9 - 12 show identical ranges as well as MboI enzyme.

Electrophoregram of HpaII-restricts' ISSR-amplification indicates to less dependence of amplicon range from exposure mode. The differences between positions 1 (seedlings from seeds without preliminary irradiation) and 7 (seedlings from preliminary gamma-irradiated seeds) are also visible because of less content of highmolecular weight fragments. Great difference of variants 9 and 10-12 that corresponds almost identical chromosome aberration yield is observed (Figure 6).

Quantify connection between changes in satellite DNA methylation patterns and chromosome aberrations' yield under various affects using Brave-Pirson's linear correlation. To perform such approach we have to suggest some principals of quantifying various changes on electrophoregrams and their degrees.

There are several significant quantitative characteristics of DNA methylation pattern changes that could be registered on electrophoregrams:

1) Change of general amplicons' number; wherein following versions are possible:

a) Changes in molecular mass of amplicons, i.e. position related to ladder bands on electrophoregram but within the amplicons' mass of control variant; nevertheless the number of new control bands or their disappearance could be various;

b) The appearance of amplicons with mass that greatly exceed the limits of control bands' mass both in the range of more high molecular mass and;

2) Change of bands' brightness-that indicates to changing number of amplicone' fragments of the same mass;

3) The combination of the listed above quantitative indicators.

Interactions between these various indicators greatly exceed the classification possibilities of changes in DNA methylation pattern and accordingly the correlation estimation between their changing rates.

Consider the simplest connection type-linear correlation between the number of amplicons and the chromosome aberrations' yield for various series of experiments. The statistical analysis for each experimental series was conducted separately.

Correlation indexes shown in Table 2 indicate to existence of significant $(\alpha=0.05)$ positive correlation between amplicons' number and chromosome aberration yield for experiments with acute UV-C exposure and MboI enzyme and significant negative correlation $(\alpha=$ $0.01)$ just for experiments with composed radiation exposure and MspI ans MboI enzymes.

To continue the correlation analysis using more detail approach via determination of 5 grades (from 0 to 4 ) of methylation patterns' varieties. It will be used following indexes:

0 - The absence of differences according to control variant;

1 - The differences in amplicons' number, which mass is in the range of control amplicons' mass;

2-The differences in amplicons' number, which mass is in the range of control amplicons' mass + differences in brightness of bands that indicates to various number of fragments in one amplicon;

3-The differences in amplicons' number, which mass is not in the range of control amplicons' mass;

4-The differences in amplicons' number, which mass is not in the range of control amplicons' mass + differ-

Table 2. The coefficient of correlation between amplicons' number and chromosome aberration yield.

\begin{tabular}{cccc}
\hline \multirow{2}{*}{$\begin{array}{c}\text { Experimental } \\
\text { series }\end{array}$} & \multicolumn{3}{c}{ Correlation Coefficient, R } \\
\cline { 2 - 4 } & MspI & HpaII & MboI \\
\hline 1. & 0.29 & - & 0.72 \\
2 & 0.69 & 0.105 & $0.82^{*}$ \\
3 & $-0.89^{* *}$ & -0.73 & $-0.89^{* *}$ \\
\hline
\end{tabular}

Significance of a correlation coefficient, ${ }^{*} \alpha=0.05,{ }^{* *} \alpha=0.01$. 
ences in brightness of bands.

Results of this way of correlation assessment are shown in Table 3.

Thus such approach for determination the degree of methylation pattern changes increased the correlation index for some variants and decreased it for another one.

Continue the specification of approach to correlation assessment via determination of 9 grades (from 0 to 8 ) of methylation patterns' varieties. It will be used following indexes:

0 - The absence of differences according to control variant;

1-The differences in amplicons' number (n), which mass is in the range of control amplicons' mass, $n \leq 3$;

2-The differences in amplicons' number (n), which mass is in the range of control amplicons' mass, $\mathrm{n} \leq 3+$ differences in their brightness;

3 - The differences in amplicons' number $(\mathrm{n}>3)$, which mass is in the range of control amplicons' mass;

4-The differences in amplicons' number $(n>3)$, which mass is in the range of control amplicons' mass + differences in their brightness;

5-The differences in amplicons' number $(\mathrm{n} \leq 3)$, which mass is not in the range of control amplicons' mass;

6-The differences in amplicons' number $(\mathrm{n} \leq 3)$, which mass is not in the range of control amplicons' mass + differences in their brightness;

7-The differences in amplicons' number $(\mathrm{n}>3)$, which mass is not in the range of control amplicons' mass;

8-The differences in amplicons' number $(\mathrm{n}>3)$, which mass is not in the range of control amplicons' mass + differences in their brightness.

Results of this way of correlation assessment are shown in Table 4.

Specification of differences between electrophoregrams and number of their grades could be continued using additional characteristics of electrophoregrams and their combination. However performed correlation analysis using three approaches allows to make general

Table 3. The coefficient of correlation between 5 grades of electrophoregram varieties and chromosome aberration yield.

\begin{tabular}{cccc}
\hline \multirow{2}{*}{$\begin{array}{c}\text { Experimental } \\
\text { series }\end{array}$} & \multicolumn{3}{c}{ Correlation Coefficient, R } \\
\cline { 2 - 4 } & MspI & HpaII & MboI \\
\hline 1 & 0.27 & - & 0.57 \\
2 & $0.81^{*}$ & 0.77 & $0.91^{* *}$ \\
3 & 0.43 & 0.43 & 0.64 \\
\hline
\end{tabular}

${ }^{*} \alpha=0.05 ;{ }^{* *} \alpha=0.01$.
Table 4. The coefficient of correlation between 9 grades of electrophoregram varieties and chromosome aberration yield.

\begin{tabular}{cccc}
\hline \multirow{2}{*}{$\begin{array}{c}\text { Experimental } \\
\text { series }\end{array}$} & \multicolumn{3}{c}{ Correlation Coefficient, R } \\
\cline { 2 - 4 } & MspI & HpaII & MboI \\
\hline 1 & 0.57 & - & 0.64 \\
2 & $0.87^{*}$ & $0.84^{*}$ & $0.89^{* *}$ \\
3 & 0.21 & 0.71 & 0.7 \\
\hline
\end{tabular}

${ }^{*} \alpha=0.05 ;{ }^{* *} \alpha=0.01$.

conclusion about existence of quantitative connection between chromosome aberration yield like both integral cell stress response and changes in satellite DNA methylation pattern.

Performed analysis also show that unique approach to quantify connection between chromosome aberration yield and their rates on electrophoregrams doesn't exist. Such suggestion points to possible difference in mechanisms of cell response to exposure type (physical exposure, exposure rate and duration and so on).

The investigation of differential gene activity using micro array methods and changes of DNA methylation pattern indicated that according to exposure type and intensity the activity of various gene groups had changed. That's for satellite DNA-its direct or indirect participation in cell stress response could be related to different mechanisms according to exposure type.

Despite of ways of satellite DNA participation in stress reaction such mechanisms are different as well as for transcribed DNA.

It should have been emphasized that for experimental series 1 with 3 polymorphic groups of plants significant correlations weren't obtained with any criteria. Reason for such phenomena is connected to original epigenetical polymorphism of biological material and deficient sampling from 6 variants for correlation assay.

\section{Conclusions}

Comparison of the results of cytogenetic analysis with changes in methylation patterns of satellite DNA after irradiation pointed out to their connections with different stress tolerance.

Change of the satellite DNA methylation profile may reflect the mobile elements activization, mostly associated with satellite DNA [13], and indicate the damage's progress. Such ability is especially essential for corn; it's known that nearly $50 \%$ satellite DNA of the plant are represented with mobile elements $[2,3,15]$.

At the same time, it can result in DNA configuration changes and has the protective effect. Since functional importance of satellite DNA was explained in part by 
conceptions, it was assumed to have a structural role in spatial organization of genome, and take part in homologous chromosomes' conjugation during meiosis and replication of chromosomes' telomeric sites [15]. Probably in this case different methylation patterns of satellite DNA, which meant various chromatin conformations, could have interactive character: specific methylation patterns of transcribed DNA may play role in transcription processes only under definite conformation of all the chromatin.

Interaction between satellite DNA methylation pattern and resistance to external exposures might have another explanation. It could result not only from efficient functioning of repair systems of spontaneous и inducible DNA injuries, but also from systems responsible for passing cell cycle checkpoints and complete repair of double-stranded DNA breaks. It was known, that effective repair of double-stranded DNA breaks with the mechanism of homologous recombination was possible only under conditions of certain level of chromatin relaxation [20], so it was also associated directly to the conformation of satellite DNA.

Thus conducted research provides grounds to suggest that satellite DNA methylation patterns and their changes might have various roles in cell response to stress factor. All the functions are mediated by conformation changes of these DNA sequences.

\section{Acknowledgements}

Funding for the study was provided by the Academy of Science of Ukraine, Grant No. III-3-08 "Epigenetic components of plant adaptation".

We thank PhD, Head of Laboratory of Molecular Genetics Morgun B.V., Institute of Cell Biology and Genetic Engineering, National Academy of Science of Ukraine for help in method mastering.

\section{REFERENCES}

[1] R. L. P. Adams, "DNA Methylation," Principles of Medical Biology, Vol. 5, 1996, pp. 33-66. doi:10.1016/S1569-2582(96)80107-3

[2] E. N. Tishchenko and O. V. Dubrovnaya, "Epigenetic Regulation. DNA Methylation of Genes and Transgenes in Plants," Logos, Kiev, 2004, 384 Pages.

[3] M.-T. Hauser, W. Aufsatz, C. Jonak and Ch. Luschnig, "Transgenerational Epigenetic Inheritance in Plants," Biochimica at Biophysica Acta, Vol. 1809, No. 8, 2011, pp. 459-468. doi:10.1016/j.bbagrm.2011.03.007

[4] A. Agorio and P. Vera, "ARGONAUTE4 Is Required for Resistance to Pseudomonas syringae in Arabidopsis," The Plant Cell, Vol. 19, No. 11, 2007, pp. 3778-3790. doi:10.1105/tpc.107.054494

[5] A. Bilichak, Y. Ilnystkyy, Y. Hollunder and I. Kovalchuk,
"The Progeny of Arabidopsis Thaliana Plants Exposed to Salt Exhibit Changes in DNA Methylation, Histone Modifications and Gene Expression," PLoS One, Vol. 7, No. 1, 2012, pp. 1-15.

[6] L. Zhong, Y. Xu and J. Wang, "DNA-Methylation Changes Induced by Salt Stress in Wheat Triticum aestivum," African Journal of Biotechnology, Vol. 8, No. 22, 2009, pp. 6201-6207.

[7] O. Kovalchuk, P. Burke, A. Arkhipov, N. Kuchma, S. J. James, I. Kovalchuk and I. Pogribny, "Genome Hypermethylation in Pinus silvestris of Chernobyl-A Mechanism for Radiation Adaptation?" Mutation Research, Vol. 529, No. 1-2, 2003, pp. 13-20. doi:10.1016/S0027-5107(03)00103-9

[8] I. Kovalchuk, V. Abramov, I. Pogribny and O. Kovalchuk, "Molecular Aspects of Plant Adaptation to Life in the Chernobyl Zone," Plant Physiology, Vol. 135, No. 1, 2004, pp. 357-363. doi:10.1104/pp.104.040477

[9] I. Pogribny, I. Koturbash, V. Tryndyak, D. Hudson, S. M. L. Stevenson, O. Sedelnikova, W. Bonner and O. Kovalchuk, "Fractionated Low-Dose Radiation Exposure Leads to Accumulation of DNA Damage and Profound Alterations in DNA and Histone Methylation in the Murine Thymus," Molecular Cancer Research, Vol. 3, No. 10, 2005, pp. 553-561. doi:10.1158/1541-7786.MCR-05-0074

[10] A. P. Kravets, T. A. Mousseau, A. V. Litvinchuk, Sh. Ostermiller and G. Vengzhen, "Changes in DNA Methylation Pattern in Weat Plants under Chronical $\gamma$-Exposure of Seeds," Cytology and Genetics, Vol. 44, No. 5, 2010, pp. 18-22. doi: $10.3103 / \mathrm{S} 0095452710050038$

[11] M. A. Coleman, E. Yin and L. Peterson, "Low-Dose Irradiation Alters the Transcript Profiles of Human Lymphoblastoid Cells Including Genes Associated with $\mathrm{Cy}$ togenetic Radioadaptive Response," Radiation Research, Vol. 164, No. 4, 2005, pp. 369-382.

doi:10.1667/RR3356.1

[12] M. Banda, A. Bommineni, R. A. Thomas, L. S. Luckinbill and J. D. Tucker, "Evaluation and Validation of Housekeeping Genes in Response to Ionizing Radiation and Chemical Exposure for Normalizing RNA Expression in Real-Time PCR," Mutation Research, Vol. 8, No. 649, 2008, pp. 126-134.

[13] A. M. Serebryanyi, "Radiation Adaptive Response as a Stress Reaction of a Cell," Radiatsionnaya Biologiya. Radioekologiya, Vol. 51, No. 4, 2011, pp. 399-405.

[14] A. Kravets, D. Sokolova, G. Vengzhen and D. Grodzinsky "Corn Plant DNA Methylation Pattern Changes at UV-C Irradiation Fractionating," Cytology and Genetics, Vol. 47, No. 1, 2013, pp. 29-35. doi:10.3103/S0095452713010052

[15] V. Hemleben, T. G. Beridze, L. Bakhman, Y. Kovarik and R. Torres, "Satellite DNA," Uspehi Biologicheskoy Khimii, Vol. 43, 2003, pp. 267-306.

[16] F. M. Ausubel, "Current Protocols in Molecular Biology," Biophotometer Operating Manual, 2004. http://www.eppendorf.com

[17] J. M. S. Bartlett and D. Stirling, "PCR Protocols," Hu- 
mana Press Incorporate, Humana, 2003.

http://www.dartmouth.edu/ eprctr/biodose2008/pdf/B10. pdf

[18] Y. M. Tikunov and L. I. Khrystaleva, "Application of ISSR Markers in the Genus Lycopersicon," Euphitica, Vol. 131, No. 1, 2003, pp. 71-80. doi:10.1023/A:1023090318492
[19] A. V. Lakin, "Biometry,” High School, Moskva, 1990.

[20] A. I. Gaziev, "Deterioration of Critical DNA Damage Repair Efficiency under Low Dose Irradiation," Radiatsionnaya Biologiya Radioekologiya, Vol. 51, No. 5, 2011, pp. 512-529. 